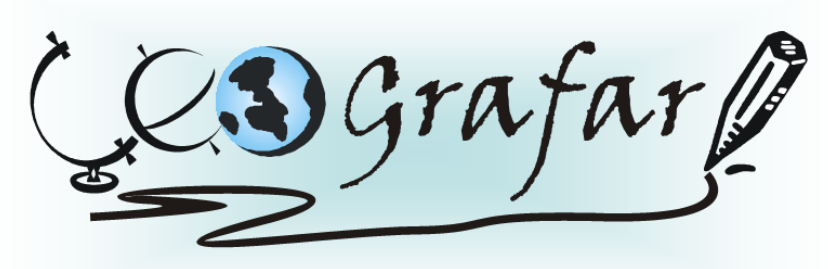

Revista Eletrônica do Programa de Pós-Graduação em Geografia - UFPR

\title{
IMPORTÂNCIA DAS WETLANDS PARA A QUALIDADE DAS ÁGUAS NA REGIÃO METROPOLITANA DE CURITIBA - PR
}

\author{
CELIA REGINA GAPSKI YAMAMOTO' \\ NALDY EMERSON CANALI ${ }^{2}$
}

\begin{abstract}
RESUMO
Diversas políticas públicas aplicadas ao solo urbano atual visam a promoção sustentável do uso dos espaços. Muitas vezes, porém, determinados instrumentos não são suficientes ou eficientes para o alcance dos resultados esperados, promovendo desvios nos objetivos projetados, cuja recondução depende de um eficiente sistema de gestão. Saliente-se as gravíssimas consequências da poluição das águas bem como a importância da gestão das wetlands para as águas e a gestão das águas para as wetlands. Os desvios entre os modelos aplicados e projetados em áreas urbanas e os ganhos em recursos hídricos podem ser detectados, permitindo o equilíbrio entre a utilização dos recursos disponíveis e o desenvolvimento sustentável das cidades e a avaliação e gestão das wetlands que se mostram potencial para a melhoria da qualidade das águas dos rios. Aplicando um ensaio metodológico baseado na metodologia GTP - Geossistema, Território e Paisagem - para uma avaliação qualitativa e quantitativa de wetlands urbanas e de utilização potencial destas para a melhoria da disponibilidade de recursos hídricos e adotando-se, como estudo de caso, parte da bacia do Alto Iguaçu na Região Metropolitana de Curitiba, Paraná, foram realizadas as análises qualitativa e quantitativa de algumas variáveis, obtendo-se a síntese necessária à priorização de ambientes potenciais para os recursos hídricos e dessa forma, contribuir com diretrizes para a requalificação do espaço (recomposição ambiental das áreas), visando a melhoria das águas urbanas e a conservação das wetlands do Alto Iguaçu e, também, a aplicação em outras bacias.
\end{abstract}

Palavras-chave: gestão urbana; gestão de recursos hídricos; wetlands; desenvolvimento sustentável.

\footnotetext{
${ }^{1}$ Graduação em Arquitetura e Urbanismo, Mestre em Engenharia - Planejamento Ambiental, Doutora em Geografia, professora do IFPR Curitiba. celiagyamamoto@gmail.com

2 Doutor em Geografia.naldy@brturbo.com.br
} 


\title{
WETLAND SYSTEMS FOR WATER QUALITY IMPROVING IN THE CURITIBA METROPOLITAM REGION - PR
}

\begin{abstract}
Several public policies applied to urban land have as objective the sustainable promotion of open spaces' use. However, sometimes the instruments are not enough or are not efficient to achieve the goals, promoting deviations in the projected objectives, whose reconveyance depends on an efficient management system. It's noticeable the serious consequences of water pollution as well as the importance of the management of wetlands for the waters and the water management for the wetlands. The deviations between the models, applied and projected on urban areas, and the gains on water resources can be detected, allowing the equilibrium between the use of natural resources, the cities sustainable development and the wetlands management, that show potential for bettering the quality of river's water. Applying, for the first time, a methodological essay based on GTP - Geosystem, Territory and Landscape- methodology, it was evaluated qualitative and quantitative aspects of the urban wetlands and their potential use for enhancing the availability of water resources on Iguaçu river basin inside the limits of Curitiba metropolitan area. Considering the results of the researched variables it was possible to achieve the necessary synthesis and the priority environments that should have their functions restored, objectifying the improving of urban water and Upper Iguaçu wetlands conservation.
\end{abstract}

Keywords: urban management; water resources management; wetlands; sustainable development.

\section{INTRODUÇÃO}

A palavra inglesa wetland, termo de uso internacional, pode ser traduzida como área úmida ou zona úmida que abrange o conjunto de diversos tipos de ecossistemas úmidos existentes que ocupam cerca de $6 \%$ da superfície terrestre (SCHUYT; BRANDER, 2004).

Neste estudo, considerou-se a definição de wetland proposta por Neiff (1999, p.102):

Sistema de cobertura onde a presença temporal de uma lâmina de água variável (espacial e temporal) condiciona fluxos biogeoquímicos próprios, solos com acentuado hidromorfismo e uma biota peculiar por processos de seleção, que tem padrões próprios em sua estrutura e dinâmica. Podem ser considerados como macrossistemas cuja complexidade cresce com a variabilidade hidrosedimentológica e a extensão geográfica ocupada. 
No Estado do Paraná, as wetlands regionais e locais apresentam um valor ecossistêmico importante para estocagem e purificação da água e recreação. Assim, na Região Metropolitana de Curitiba, RMC, um dos maiores desafios é o gerenciamento e a gestão de suas wetlands, altamente urbanizadas e povoadas, com evidentes interferências na qualidade das águas, degradadas pelas atividades antrópicas, gerando situações potenciais de escassez de água para o consumo humano em condições adequadas de qualidade. São, em sua aparente banalidade, uma verdadeira riqueza regional, necessitando serem administradas, valorizadas e apreciadas. Trata-se de um recurso que foi diferentemente valorizado e artificializado pelos sistemas econômicos que se sucederam.

Essas áreas úmidas têm-se mostrado eficientes em remover/degradar/reter nutrientes, compostos orgânicos e inorgânicos naturais ou sintéticos, materiais tóxicos que fluem por estes ambientes (SAHAGIAN; MELACK, 1998; MITSCH; GOSSELINK, 2000; MMA, 2006a).

Sua conservação é condição indispensável para a concretização do desenvolvimento sustentável, sendo o reconhecimento de sua importância, por parte de órgãos governamentais, instituições privadas, e da sociedade em geral, o primeiro passo. As wetlands estão entre os ecossistemas mais produtivos do planeta em termos de produção primária e secundária; representam abrigos e áreas de alimentação, reprodução e crescimento de muitas espécies de ambientes vizinhos (rios, lagoas, matas...) e de outras regiões do planeta, como no caso das aves migratórias. Também podem filtrar as impurezas carregadas pela água dos rios; regulam o volume de água dos ambientes aquáticos na ocasião de grandes chuvas e são grandes reservatórios de carbono (IBAMA, 2010).

Partindo-se da premissa de que a sustentabilidade econômica, social e ambiental da Região Metropolitana de Curitiba - RMC - passa pela consideração da urgência em atenuar os impactos negativos das relações entre desenvolvimento urbano e disponibilidade dos recursos hídricos, é indispensável, contribuir com a avaliação e gestão das várzeas -wetlands regionais- que se mostram potenciais para a melhoria da qualidade das águas dos rios.

O conceito de sustentabilidade, por sua vez, considera que há uma resiliência nos ecossistemas e, portanto, uma capacidade de uso (ALMEIDA, 2007). Os sistemas de wetlands não são frágeis, uma vez que derivam das próprias 
alterações a que foram submetidos, retendo considerável biodiversidade, embora, também, não sejam infinitamente resilientes (TASSI, 2007).

Os indicadores de estado podem ser entendidos como "elementos" que compõem a mesma e permitem investigar o grau de perturbação ao qual está submetida, avaliar a resiliência, além de se constituírem em importante ferramenta quando o assunto é recuperação ambiental (TASSI, 2007). Qualidade de água, fitoplâncton, zooplâncton, peixes e vegetação foram utilizados como indicadores de estado, interpretados como sendo de relevante importância para a mudança da biodiversidade e dos estados de qualidade.

Este artigo apresenta aspectos relacionados a quatro dos objetivos específicos trabalhados por Yamamoto (2011): inventariar tipos ocorrentes na bacia do Alto Iguaçu; avaliar a qualidade da água em algumas e propor ferramentas de proteção/manutenção e restauração das suas funções.

Uma política moderna baseada em conhecimento científico e capaz de conciliar desenvolvimento econômico com a proteção ambiental e bem-estar social se faz necessária. Esta política deve considerar o valor das wetlands e seus serviços ambientais, além de sua importância para a biodiversidade.

\section{REFERENCIAL TEÓRICO}

O conceito de bacia hidrográfica ajuda a colocar em perspectiva muitos dos problemas e conflitos, podendo ser citado que as causas e as soluções da poluição da água não serão encontradas olhando-se apenas para o canal fluvial, sendo necessário considerar a bacia de drenagem inteira como unidade de gerenciamento. Assim, os campos, as florestas, as massas de água e as cidades, interligadas por um sistema de rios ou canais interagem como uma unidade prática tanto para o planejamento como para o gerenciamento (ODUM, 1988).

A fragmentação de áreas naturais e destruição das conexões hidrológicas tem resultado em bacias degradadas funcionalmente, nas quais os problemas de qualidade das águas ocorrem regularmente (VERHOEVEN et al., 2008).

A deterioração da qualidade das águas, a impermeabilização, a perda do meandrar como um processo natural do rio, com a construção de obras de engenharia sobre os rios, canalização, retificação, drenagem, polderização, 
represamento, entre outras, ao alterar o regime hidrológico, produzem efeitos concatenados sobre as wetlands da bacia (NEIFF, 1999; VERHOEVEN et al., 2008).

As várzeas, frequentemente drenadas ou aterradas, e também recheadas de tubulações de drenagem urbana, que favorecem que as águas da cidade cheguem diretamente aos rios, e o estado da deterioração da qualidade das águas fluviais atestam a importância de medidas de restauração auto-sustentável dos processos e suas funções (VERHOEVEN et al., 2008).

Uma alternativa possível para limpar a água é o tratamento das águas do rio a montante de sua foz ou ainda imediatamente a jusante do lançamento de efluentes urbanos. Técnicas e sistemas sustentáveis com boa performance custo/benefício podem assumir diferentes formas e incluem: wetlands construídas, restauradores e filtros.

Filtros subterrâneos podem ser usados como opção de tratamento sem adição de produtos químicos, tanto de águas residuárias (BRIX; ARIAS, 2005) como de águas dos rios conforme experiência de purificação do rio Tama, Japão, com a instalação de filtros de pedregulho em três de seus afluentes. A água afluente aos sistemas Nogawa, Hirasegawa e Yajigawa com DBO de 13, 20 e 15 mg/L foi devolvida aos rios com DBO entre 0,5 e $1,5 \mathrm{mg} / \mathrm{L}$, resultando em uma eficiência superior a 90\% (Japão, 198-?).

Fuzhou, China, uma cidade com, aproximadamente, 3 milhões de habitantes na bacia do Min River, com seus canais históricos cheios de lixo, esgoto in natura e sedimentos, adotou uma solução não convencional. Living machines, restauradores (tradução da autora) foram instalados ao longo de $600 \mathrm{~m}$ do canal de Baima, que recebia esgoto de 12.000 pessoas, resultando em uma bela estrutura (

Figura 1) e um sistema funcional que custou 1/8 do custo de um tratamento convencional de esgotos. Após um ano de operação, as águas ao longo do canal se tornaram claras, sem odor desagradável e ainda contendo muitos peixes, tempo em que os vizinhos do canal relataram terem visto borboletas e pássaros pela primeira vez em suas vidas. Os índices de amônia (de 80 ppm para 10 a 15 ppm) e DBO (de $150 \mathrm{mg} / \mathrm{L}$ para $15 \mathrm{mg} / \mathrm{L}$ ) decresceram, enquanto o oxigênio dissolvido (de 0,3 e 0,5 $\mathrm{mg} / \mathrm{L}$ para $6 \mathrm{mg} / \mathrm{L}$ ) foi aumentado (CHARMAN, 2004). 
Figura 1 - Restauradores Living Machines, Canal de Baima, China
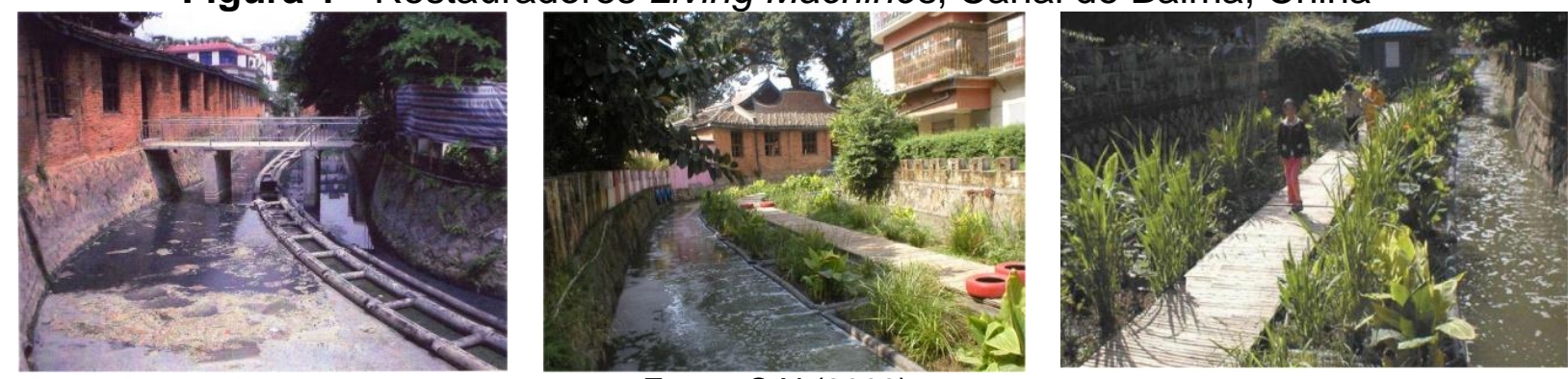

Fonte: OAl (2008)

Wetlands construídas vegetadas atuam para a recuperação de um sítio ou lugar após ter sido impactado por poluição ou extração e, também, como habitat da vida selvagem (MOLLE et al., 2005). Os sistemas com plantas são eficientes porque o processo de degradação da matéria orgânica (mineralização, nitrificação, desnitrificação) é muito completo, devido à grande biomassa. Além disso, são removidos não só nutrientes (por exemplo, fosfatos) que levam a eutrofização das águas, mas também coliformes e substâncias inorgânicas, como metais pesados. Os custos de operação e manutenção são extremamente baixos. Podem ser, se desejável, configurados como elementos de paisagismo, por exemplo, em forma de jardins e parques (FATMA, 2002), que foi o caso de wetland na ilha de Koh Phi Phi Don.

Um sistema múltiplo com área total de $6000 \mathrm{~m}^{2}$, composto de wetlands construídas de fluxo vertical $\left(2.300 \mathrm{~m}^{2}\right)$, de fluxo subsuperficial horizontal, de fluxo superficial horizontal $\left(1.500 \mathrm{~m}^{2}\right)$ e lagos $\left(200 \mathrm{~m}^{2}\right.$ ) (Figura 2) trata $400 \mathrm{~m}^{3} / \mathrm{d}$ de esgotos de um hotel incorporando-se como jardins. O sistema remove os contaminantes e retorna a água para reúso nos hotéis, restaurantes e residências da ilha. As espécies utilizadas foram variedades de Canna e Heliconia (KONNERUP; BRIX, 2008). 
Figura 2 - Wetland construida de Koh Phi Phi Don

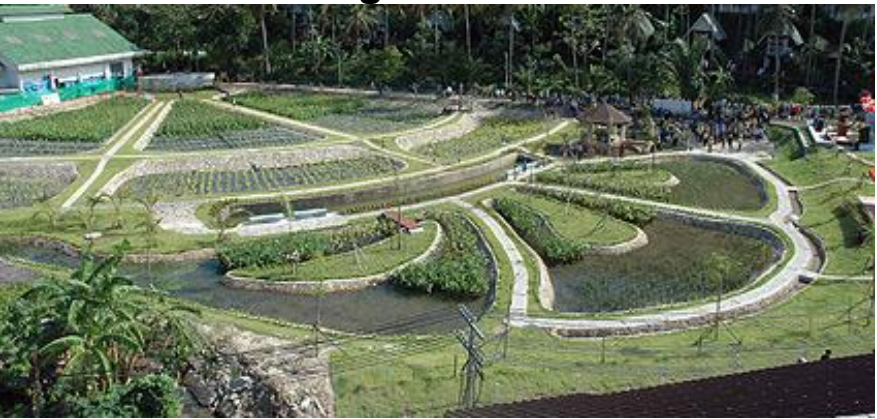

Vista aérea do sistema

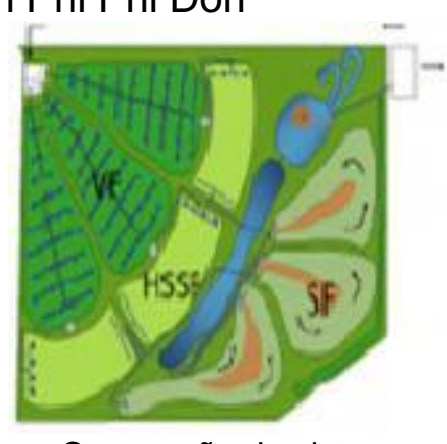

Concepção do sistema

Fonte: http://www.cowi.com; Laugesen et al., 2010

Nota: VF - wetlands de fluxo vertical; HSSF - wetlands de fluxo subsuperficail horizontal; SF _ wetlands de fluxo superficial horizontal

\section{METODOLOGIA}

\section{1 ÁREA DE ESTUDO}

A situação de comprometimento dos rios é resultado de um processo de mais de trezentos anos de história de ocupação. O Passeio Público, primeiro parque de Curitiba, se concretiza, em 1886, a partir dos trabalhos de saneamento do rio Belém, famoso por suas áreas de terrenos alagadiços (DUARTE; GUINSKI, 2002), considerados áreas insalubres e que deviam ser "saneados", ou seja, deveriam ser transformados em outro tipo de ambiente (pela drenagem, aterro ou qualquer outra forma) (VITOR, 1996). A água, em seu sentido geral, se tornou um dos elementos direcionadores da expansão urbana (TREVISAN, 2004).

Os aluviões que caracterizam, preliminarmente, as wetlands do Iguaçu, mais conhecidas como as várzeas do rio Iguaçu, representam $16 \%$ da área da bacia do Alto Iguaçu, e $15 \%$ desses encontram-se em áreas já urbanizadas, apresentando alterações antrópicas de magnitude.

A Figura 3 apresenta, em vermelho, a espacialização de $68 \mathrm{~km}^{2}$ resultante da superposição das áreas urbanas, com a classe aluviões e terraços aluvionares. Apresenta, também, (em azul) as áreas alagadas e de cavas $\left(39 \mathrm{~km}^{2}\right)$ na bacia do Alto Iguaçu, que ocorrem nas áreas de aluviões atuais na bacia de gestão do Alto Iguaçu. 
Figura 3 - Aluviões em áreas urbanizadas da Bacia do Alto Iguaçu

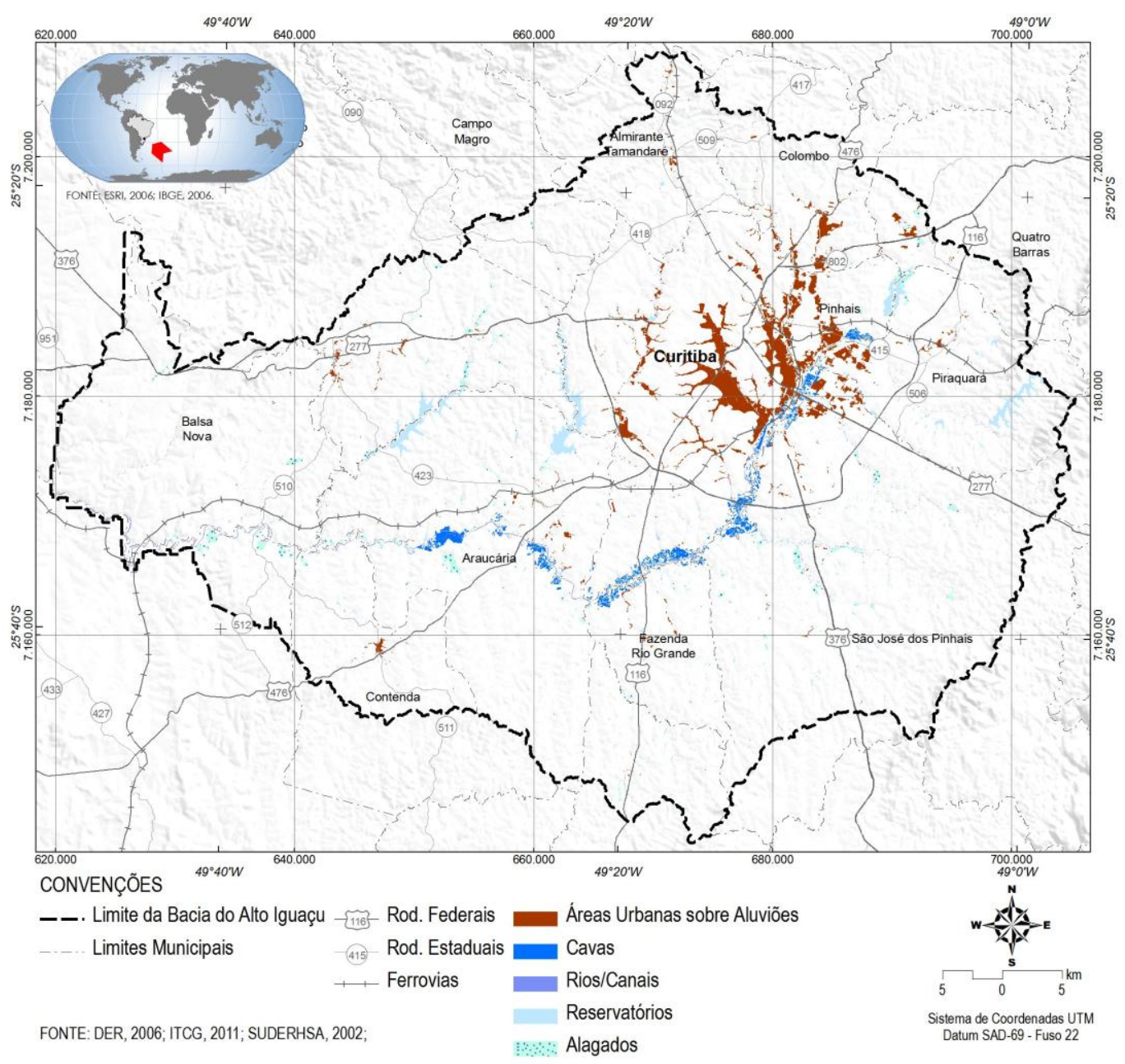

Muitos municípios da bacia, a exemplo de Curitiba, drenaram e ocuparam suas várzeas. Várias intervenções se realizaram com o propósito de sanear as áreas alagadiças, ganhar terreno aproveitável e evitar os efeitos das enchentes (LANGE, 2005).

Após a grande inundação de 1995, adotaram-se medidas de controle: ampliação da capacidade de escoamento com a execução do canal paralelo e retificação dos meandros do rio Iguaçu, construção de diques laterais, a implantação do Parque Metropolitano do Iguaçu e, posteriormente a elaboração do plano diretor de drenagem (SUDERHSA, 2002).

O sistema fluvial Iguaçu apresenta-se na atualidade como um canal duplo em sua parte de montante. A retificação do curso do rio Iguaçu, eliminando sua característica meandrante, conferiu-lhe um traçado retilíneo de $30 \mathrm{~m}$ de largura média ao longo de $29 \mathrm{~km}$, entre a PR-415 e a BR-116. A abertura do canal paralelo, que inicia no rio Irai, a jusante do rio Piraquara e PR 415, se desenvolve paralelo à 
margem esquerda do rio Iguaçu até além do Contorno Leste, às proximidades da foz do rio Miringuava, numa extensão de 20 km, conforme ilustrado na Figura 4.

Assim, há que ressaltar que as planícies de inundação e os rios não são os mesmos rios e planícies anteriores à urbanização. Se na planície original as inundações sazonais eram naturais, não são mais as mesmas inundações que atualmente ocorrem, devido às alterações do curso dos rios e da várzea em certas partes de forma irreversível, a menos que um brutal reordenamento urbano seja realizado.

Figura 4 - Canal extravasor, retificação e alargamento do rio Iguaçu

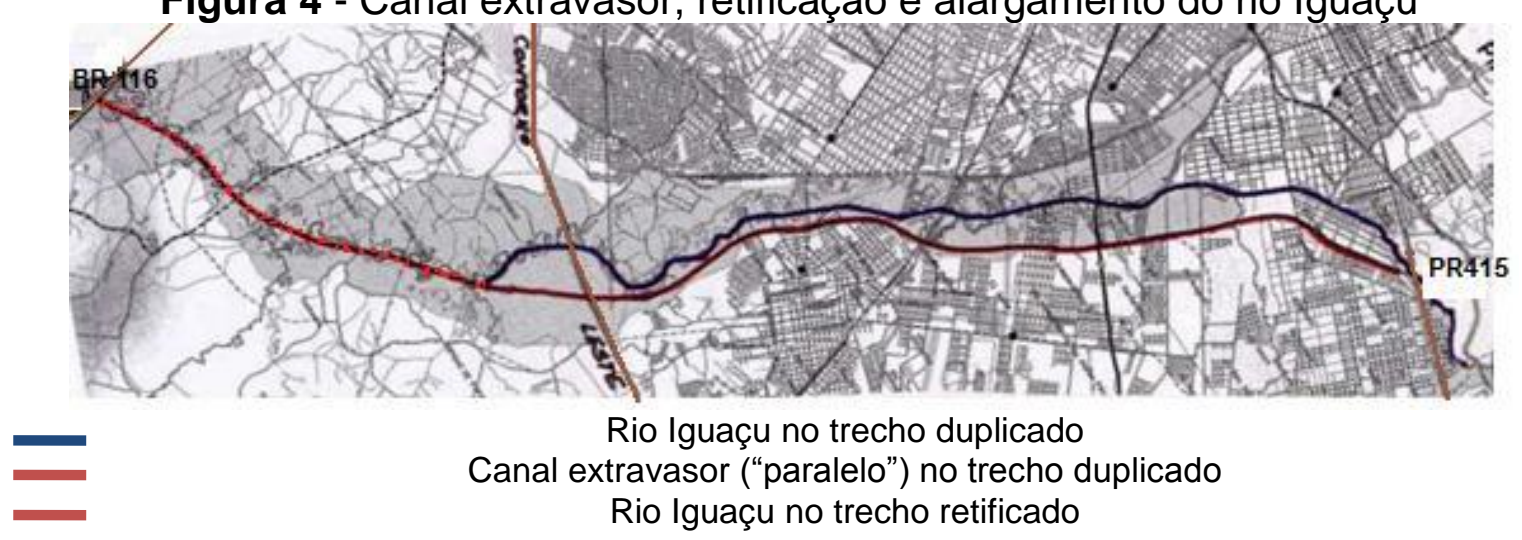

Este mergulho na história permitiu concluir que os problemas das cidades, em especial dos rios poluídos e do uso inteligente das várzeas, não foram enfrentados na RMC. O aumento populacional e o crescimento econômico exigiram maiores demandas e imprimindo maior consumo dos recursos naturais, exerceram influências negativas sobre os sistemas fluviais.

\subsection{PROCEDIMENTOS METODOLÓGICOS}

Para dar conta da análise e compreensão dos processos atuais entre as interações da sociedade moderna e da natureza, e da avaliação das wetlands, visto que o estado atual na área de estudo é de uma situação de conflito pelo uso da água num quadro de intenso processo de degradação ambiental, é aplicado o que Bertrand e Bertrand (2007) propõem: o uso da abordagem tripolar - GTP GEOSSISTEMA-TERRITÓRIO-PAISAGEM. Esta abordagem associa o geossistema ao território e à paisagem, três categorias espaço-temporal diferentes, mas 
complementares. O Geossistema permite um esboço de análise espaço-temporal através do seu grau de antropização, por suas características espaciais, biogeoquímicas de sua água e de seus ritmos hidrológicos. O Território permite analisar as repercussões da organização e dos funcionamentos sociais e econômicos sobre o espaço considerado: os atores, individuais ou coletivos, atuais ou passados que intervêm no território considerado; correspondendo à análise da gestão. A Paisagem representa a dimensão sociocultural do mesmo conjunto geográfico: os tipos de relações entre os lugares e os atores da paisagem, individuais ou coletivos, que intervêm diferentemente na paisagem, enquanto estados paisagísticos da sociedade.

Nesta área foi avaliada a qualidade das águas, aspecto analisado por Yamamoto (2011), indicador de estado dos ambientes wetlands. Diferentes campanhas, realizadas entre abril de 2008 e dezembro de 2010, são apresentadas em Tabela 1 e Figura 5.

Tabela 1 - Pontos de amostragem

\begin{tabular}{|c|c|c|c|c|c|c|c|}
\hline \multicolumn{2}{|c|}{ Ambiente } & Código & \multicolumn{2}{|c|}{ Coordenadas } & 2008 & 2009 & 2010 \\
\hline \multirow{5}{*}{$\begin{array}{l}\text { Wetlands } \\
\text { construídas }\end{array}$} & \multirow{3}{*}{ Cidade Jardim } & CJ1 & 7175695 & 679418 & & $x$ & $x$ \\
\hline & & CJ2 & 7176471 & 679923 & & $x$ & $x$ \\
\hline & & CJ3 & 7175818 & 679421 & & $\mathrm{X}$ & $\mathrm{X}$ \\
\hline & São Judas & SJ1 & 7180020 & 681838 & & $\mathrm{X}$ & $\mathrm{X}$ \\
\hline & Tadeu & SJ2 & 7180024 & 681809 & & $\mathrm{X}$ & $\mathrm{x}$ \\
\hline \multirow{3}{*}{ Cavas } & Cavas & P3 & 7182125 & 683748 & $\mathrm{X}$ & $\bar{X}$ & \\
\hline & montante BR- & P4 & 7181677 & 683608 & $\mathrm{X}$ & $\mathrm{X}$ & $\mathrm{X}$ \\
\hline & 277 & P5 & 7180082 & 682827 & $X$ & $\mathrm{X}$ & \\
\hline \multirow{19}{*}{$\begin{array}{c}\text { Ambientes } \\
\text { Lóticos }\end{array}$} & \multirow{3}{*}{ Rio Iraí } & & continua & & & & \\
\hline & & IR1 & 7184731 & 689136 & & $\mathrm{X}$ & $\mathrm{X}$ \\
\hline & & IR2 (P1) & 7183475 & 683876 & $\mathrm{X}$ & $\mathrm{X}$ & $\mathrm{X}$ \\
\hline & \multirow{3}{*}{ Canal paralelo } & CE1 & 7182890 & 684072 & & $\bar{X}$ & $X$ \\
\hline & & CE2 & 7182200 & 683823 & $\mathrm{X}$ & $\mathrm{X}$ & $\mathrm{X}$ \\
\hline & & CE3 & 7180039 & 682888 & & $x$ & $x$ \\
\hline & \multirow{3}{*}{ Rio Palmital } & PA1 & 7189118 & 648985 & & & $\mathrm{X}$ \\
\hline & & PA2 & 7190313 & 683756 & & & $\mathrm{X}$ \\
\hline & & PA3 & 7184681 & 684259 & & & $\mathrm{X}$ \\
\hline & \multirow[b]{2}{*}{ Rio Atuba } & AT1 & 7184868 & 681040 & & & $\mathrm{X}$ \\
\hline & & AT2 & 7181323 & 682422 & & & $\mathrm{X}$ \\
\hline & \multirow{4}{*}{ Rio Itaqui } & TQ1 & 7175514 & 691808 & & $\mathrm{X}$ & $\mathrm{X}$ \\
\hline & & TQ2 & 7178203 & 688980 & & & $x$ \\
\hline & & TQ3 & 7178651 & 688052 & & $\mathrm{X}$ & $x$ \\
\hline & & TQ4 & 7181674 & 685817 & & $\mathrm{X}$ & $\mathrm{X}$ \\
\hline & \multirow{3}{*}{ Rio Pequeno } & PQ1 & 7170685 & 700845 & & & $\mathrm{X}$ \\
\hline & & $P Q 2$ & 7179996 & 683922 & & $X$ & $\mathrm{X}$ \\
\hline & & PQ3 & 7180080 & 682914 & & $\mathrm{X}$ & $\mathrm{X}$ \\
\hline & Rio Iguaçu & IG1 & 7180213 & 681965 & & $\mathrm{X}$ & $\mathrm{X}$ \\
\hline
\end{tabular}


Figura 5 - Localização dos pontos e ambientes de amostragem

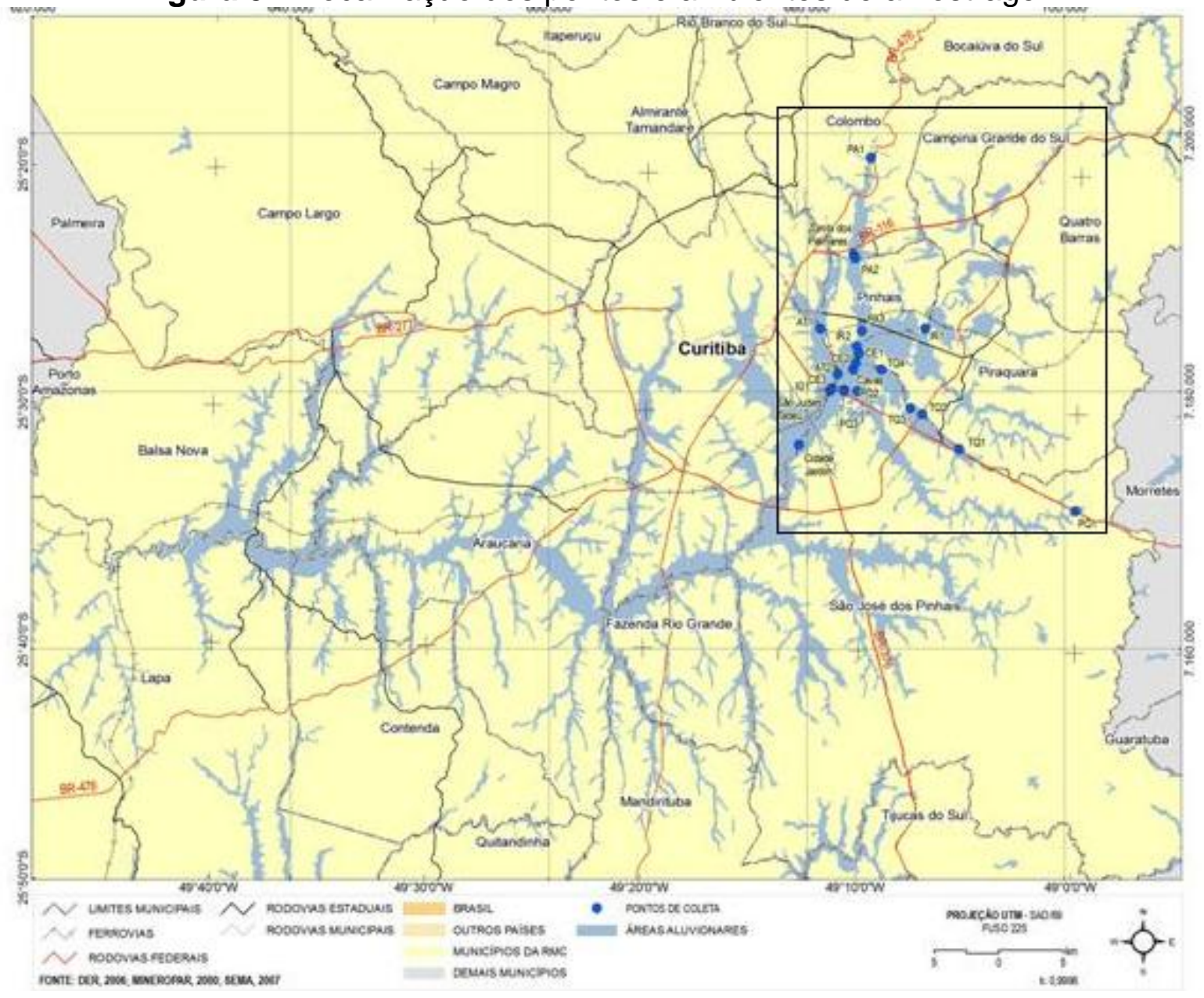

Os locais monitorados com a parceria entre o Instituto das Águas do Paraná (AGUASPARANA), Universidade Tecnológica do Paraná (UTFPR) e Instituto Ambiental do Paraná (IAP) foram:

_ cavas de areia: parcela das cavas de areia do rio Iguaçu. Área explorada pela atividade mineradora por décadas, produzindo com esta atividade, mais de 65 cavas na área de estudo a montante da BR-277, entre canal extravasor e rio Iraí, com profundidades entre $1,00 \mathrm{~m}$ e 4,50 m, totalizando uma superfície de lâmina d'água de $1.040 .185 \mathrm{~m}^{2}$ e volume aproximado de 2,5 milhões de metros cúbicos (SANEPAR, 2006);

_ rio Iraí, principal manancial da bacia do rio Iguaçu na RMC: O reservatório do Iraí recebe as águas de uma bacia de drenagem de $113 \mathrm{~km}^{2}$ e supre o abastecimento público de água para mais de um milhão de pessoas da RMC (ANDREOLI 2003); 
_ canal paralelo: inicia-se próximo à captação Iraí. Após receber os rios Itaqui e Pequeno (via lagoa-reservatório da Corina), as águas do canal passam por baixo do leito do rio Iguaçu através de um sifão, sendo dirigidas à captação Iguaçu. Segue "paralelo" ao rio Iguaçu até a foz do rio Miringuava. (SUDERHSA, 2007);

_ rio Itaqui: drena os municípios de Piraquara e São José dos Pinhais, e recebe as águas residuárias da Estação de Tratamento de Esgotos Martinópolis, cuja eficiência média de DBO é de 81\% (AGUASPARANA, 2011a). Destaca-se o fato de esta bacia apresentar densa ocupação com numerosas vilas e favelas (IAP, 2009);

_ lagoa do Itaqui: resultante de represamento por uma barragem de pequena altura para operação de um pesque pague, contribui significativamente no amortecimento das enchentes da região, podendo acumular $587.805 \mathrm{~m}^{3}$ de água (COPEL, 2007). Está localizada a jusante da ETE Martinópolis entre o Contorno Leste e a foz do rio Itaqui no canal de água limpa;

_ lagoas ou bacias de retenção nas localidades de Cidade Jardim e São Judas Tadeu (município de São José dos Pinhais, bacia do rio Iguaçu);

_ rio Pequeno, que drena uma bacia de $134 \mathrm{~km}^{2}$ (SANTOS, 2001);

_ rio Palmital: tem suas nascentes no município de Colombo, atravessa a área urbana dos municípios de Colombo e Pinhais e tem sua foz no rio Iraí, a jusante da captação Iraí, situação que implica numa combinação de águas no ponto amostrado, onde predominam as características do rio Palmital;

- rio Atuba: é o elemento separador dos territórios de Curitiba e Pinhais. Após receber os efluentes da ETE Atuba Sul, une-se ao rio Iraí para formar o rio Iguaçu.

Para realização de todas as análises, os materiais foram previamente descontaminados. A água, para as análises físicas e químicas em laboratório, foi coletada com garrafas de Van Dorn, armazenadas e preservadas em gelo até o deslocamento ao laboratório onde foram armazenadas a $4^{\circ} \mathrm{C}$ até serem realizadas todas as análises. As análises físicas e químicas da água foram realizadas em amostras in natura e filtradas. As filtrações foram realizadas utilizando-se membranas Millipore de éster de celulose, 0,45 $\mu \mathrm{m}$. 
Em campo foram obtidos valores de temperatura da água e ar, $\mathrm{pH}$ (pHmetro Digimed-DM2), oxigênio dissolvido (Oxímetro Digimed-DM4), intensidade luminosa e profundidade (disco de Secchi) da água.

No laboratório da UTFPR foram analisados os parâmetros: N-nitrito (método colorimétrico), N-nitrato (método da redução do Cádmio), N-amoniacal (método de fenato), ortofosfato (método do ácido ascórbico) e fósforo total dissolvido (digestão ácida, método do ácido ascórbico), todos os métodos descritos por APHA (1998).

A partir de amostras in natura foram quantificadas a concentração de fósforo total e demanda química de oxigênio (APHA, 1998). As análises de cloreto seguiram o método titulométrico do nitrato mercúrico, a de sólidos dissolvidos pelo método gravimétrico e a clorofila seguiu o método proposto pelo Instituto Ambiental do Paraná, através de extração com álcool etílico. O teste de alcalinidade foi realizado logo após a coleta, já no laboratório, através do método Gran. A concentração de carbono orgânico dissolvido - COD - foi determinada empregando o equipamento TOC 5000-A Shimadzu em amostras filtradas (APHA, 1998). A determinação da cafeína foi realizada por cromatografia líquida na UFPR.

As análises de demanda bioquímica de oxigênio - DBO, Escheria. coli e Coliformes totais foram realizadas nos laboratórios do Instituto Ambiental do Paraná.

\section{RESULTADOS E DISCUSSÕES}

A poluição faz-se sentir na RMC na bacia do Altíssimo Iguaçu, indicando que essa situação decorre da ausência de uma política urbana integrada às demais políticas públicas, refletida em grandes concentrações urbanas ao longo do Iguaçu e seus afluentes, parcialmente beneficiadas por serviços de saneamento básico e drenagem urbana. O remanescente de DBO que alcança os corpos d'água, através do escoamento superficial, das redes de drenagem ou de esgotos ou do lançamento de efluentes de ETEs, compromete, assim, a sua disponibilidade para usos mais exigentes (SUDERHSA, 2007), entre os quais deveria estar incluída a paisagem urbana. O mau odor prejudica os serviços ambientais culturais, como o lazer e o turismo, conforme colocado por Almeida (2007).

Além destes prejuízos há que ainda ser considerado a questão relacionada ao valor das propriedades urbanas. Num primeiro instante, as leis de zoneamento 
permitem, com a definição de coeficientes de aproveitamento elevados, um aumento de concentração populacional e de valor da terra. Num segundo momento, com uma carga poluidora produzida e lançada no ambiente, além da sua capacidade de carga, tem-se a perda da qualidade ambiental. O odor é apenas uma manifestação da perda do saudável, levando quem tem melhores condições a buscarem novos locais de moradia, deixando para traz uma propriedade com valor depreciado.

Ambientes construídos para contenção de cheias (Wetlands construídas)

As águas afluentes às bacias de retenção (Figura 6) oriundas de drenagem, portanto de run-off superficial, alcançam as lagoas, principalmente por canais revestidos ou não e por tubulações de concreto das galerias de águas pluviais. Concebidas do ponto de vista de armazenamento temporário de run-off situam-se no exutório de bacias de contribuição que abrigam assentamentos que outrora foram atingidos por enchentes fluviais.

Em geral os taludes apresentam inclinação de 1:1, considerados inadequados (NOVILLO, 2008). A adoção de taludes "solo-consumptivos" de 2:1, 3:1 ou mais é recomendado, ou outras ecotecnologias (CORTES et al., 2004; CWP, 2009), que além de resolverem a questão da estabilidade das margens, contribuem para a qualificação da vegetação, uma vez que essas lagoas não apresentam pré tratamento, sendo elas próprias as estruturas de pré-tratamento das águas de runoff afluentes aos rios.

Apresentam vegetação excessiva ou ausência, resultados de ausência de plano de manejo. Os mecanismos de tratamento não foram efetivos, também, dado a existência de curtos-circuitos (linha de fluxo muito curta entre entrada e saída) (Figura 6a e Figura 6b).

Figura 6 - Lagoas de retenção de Cidade Jardim e São Judas Tadeu

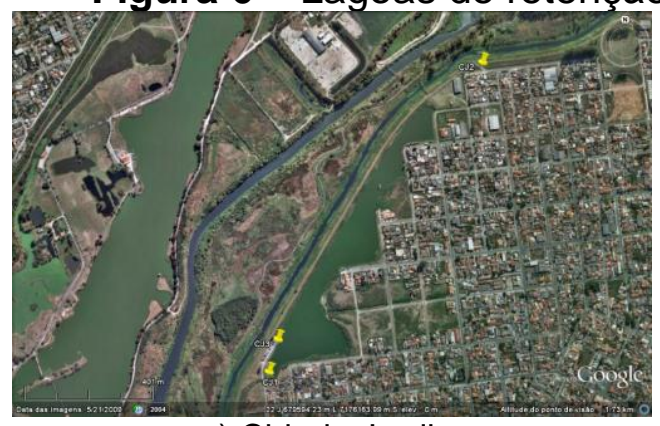

a) Cidade Jardim

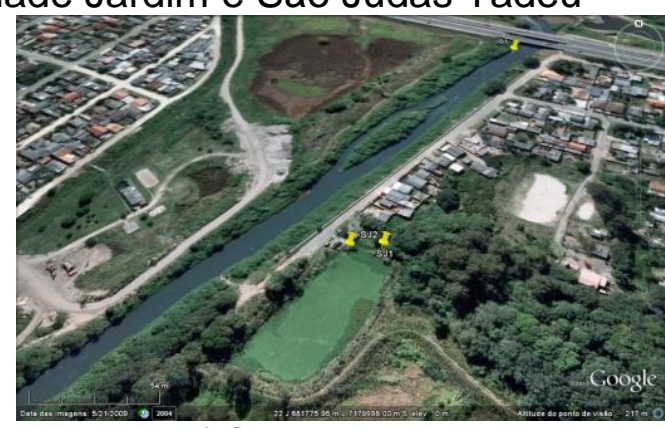

b) São Judas Tadeu 


\section{a) Lagoa do São Judas Tadeu}

Este ambiente apresenta-se dominado por macrófitas aquáticas, devido à entrada de efluentes domésticos (esgotos) que carrearam e acumularam nutrientes neste ambiente que apresenta água parada, propiciando assim sua eutrofização. Esta entrada de esgotos foi confirmada através dos altos valores de E. coli, os quais foram superiores a 1.600.000 (NMP/100 mL). Neste ambiente também foi observado um odor forte e desagradável, proveniente da decomposição de matéria orgânica no sedimento, provavelmente, do acúmulo de material proveniente das macrófitas nos sedimentos. A entrada de esgotos e sua decomposição liberou grandes quantidades de nutrientes para a coluna de água, como foi observado em termos de $\mathrm{N}$-amoniacal que apresentou valor médio de 12,36 $\pm 7,80 \mathrm{mg} / \mathrm{L}$ (máximo de $28,59 \mathrm{mg} / \mathrm{L}$ ) e de Ptotal com valor médio de 7,89 $\pm 5,45 \mathrm{mg} / \mathrm{L}$ (máximo de 15,32 mg/L).

\section{b) Lagoa da Cidade Jardim}

Lagoa que apresenta normalmente bloom de fitoplâncton, principalmente próximos aos canais, carreando esgotos para a lagoa, que foram comprovados pelos altos valores de $E$. coli (> 1.600.000 NMP/100 mL), valor máximo de fósforo total de 7,45 mg/L e de $\mathrm{N}$-amoniacal de 18,07 mg/L, determinados nas águas destes canais.

Os ambientes das lagoas de retenção São Judas Tadeu e Cidade Jardim caracterizam bem a falta de cuidados pelos gestores, pelo fato da entrada de esgotos e falta manejo. Com a adoção das medidas de controle, obtém-se uma redução de 7 a 10 vezes no valor do investimento da solução de drenagem (SUDERHSA, 2002), que pode ser canalizada para a urbanização e tratamento da paisagem.

Cavas de areia existentes entre a BR-277 e a Avenida Iraí e entre o Rio Iraí e o Canal Extravasor

As cavas, resultado do processo de extração, apresentaram os melhores resultados de qualidade da água. Isto porque as lagoas originadas após a extração de areia (P3, P4 e P5) e limitadas pelo canal extravasor (P2) e rio Iraí (P1) não recebem influência direta de cargas de efluentes domésticos ou industriais (Figura 
7). Os valores apresentados, a seguir (Figura 8 e Figura 9), resultam de 13 coletas: C1 (01/04/08); C2 (02/06/08); C3 (03/08/08); C4 (04/10/08); C5 (05/11/08); C6 (06/02/09); C7 (07/06/09); C8 (08/08/09); C9 (09/11/09); C10 (10/02/10); C11 (11/05/10); C12 (12/08/10); C13 (13/11/10).

Figura 7 - Localização dos pontos de coleta na região das cavas. P1 no rio Iraí; P2 no canal extravasor; P3, P4 e P5 nas cavas

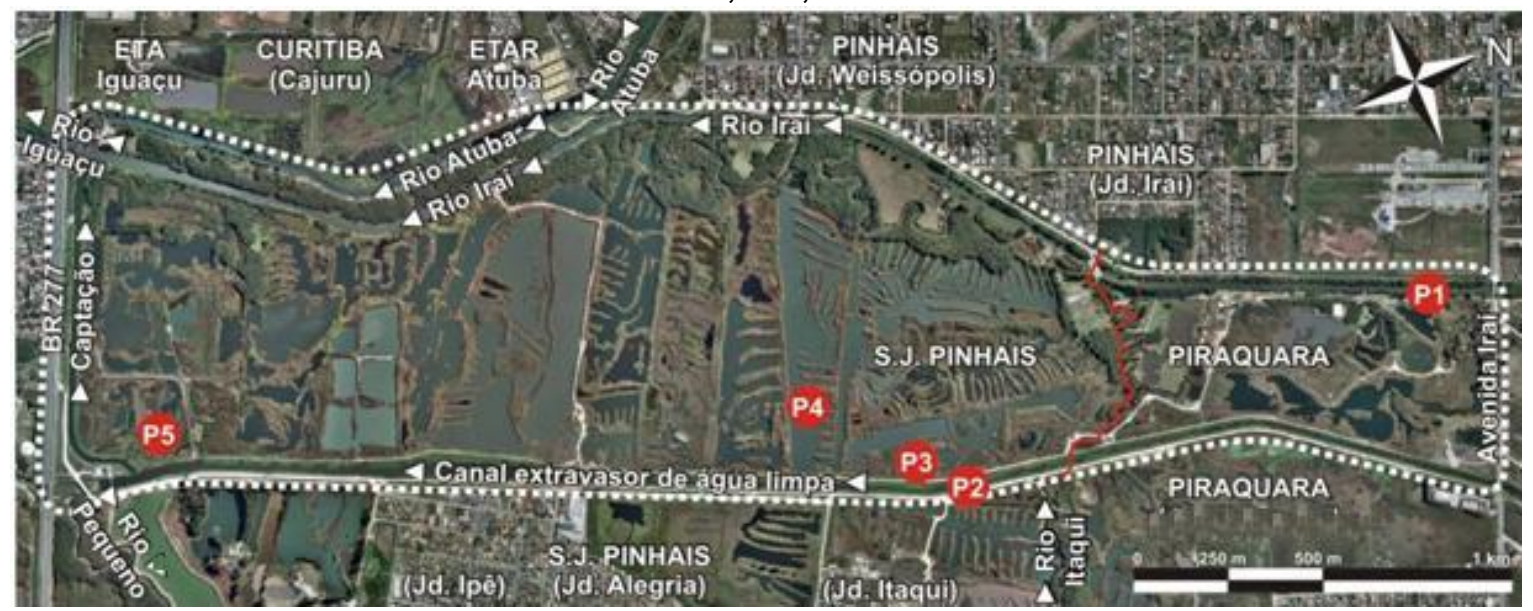

Fonte: adaptado de Google Maps, 2009.

Nos pontos P3 e P4 foram obtidos baixos valores médios de $E$. coli $(<7.000$ $\mathrm{NMP} / 100 \mathrm{~mL}$ ); 0,047 $\pm 0,061 \mathrm{mg} / \mathrm{L}$ de P-total (Figura 8a), 0,054 $\pm 0,058 \mathrm{mg} / \mathrm{L}$ de Namoniacal (Figura 8b) e maiores quantidades de oxigênio dissolvido (Figura 9), confirmando a pouca influência de efluentes neste sistema, pois no rio Iraí os valores médios foram de 1.000.000 NMP/100 mL E. coli, $784 \pm 521 \mu \mathrm{g} / \mathrm{L}$ de P-total e chegou a $3220 \pm 1780 \mu \mathrm{g} / \mathrm{L}$ de $\mathrm{N}$-amoniacal. Já o canal extravasor apresentou valores médios de $79.000 \mathrm{NMP} / 100 \mathrm{~mL}$ E. coli; $183 \mu \mathrm{g} / \mathrm{L}$ de P-total e $274 \pm 95 \mu \mathrm{g} / \mathrm{L}$ de Namoniacal.

As concentrações no canal extravasor foram menores que as do rio Iraí pelo fato de receber descarga de rios (Itaqui e Pequeno) que passam por regiões com menor densidade populacional, o que não é observado no rio Iraí, que recebe as águas do rio Palmital. 
Figura 8 - Variação da concentração de P-total e de N-amoniacal nos pontos amostrados nas cavas, rio Iraí e canal extravasor

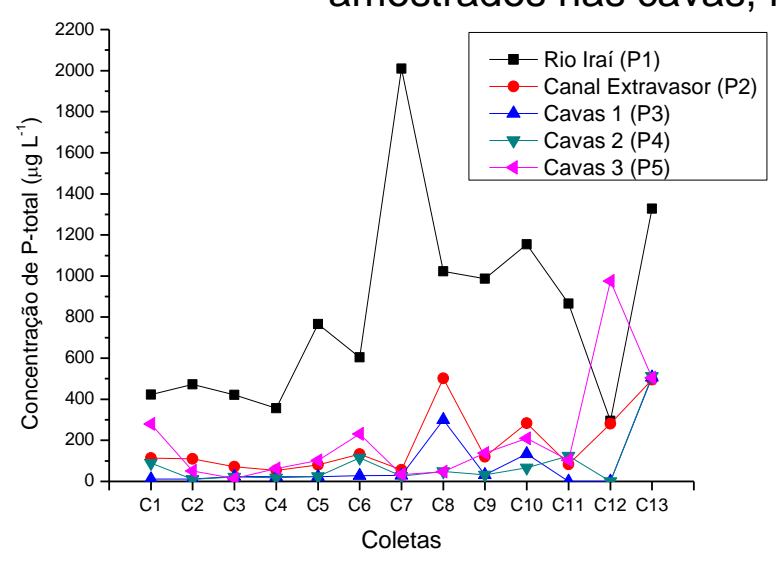

a) Variação da concentração de P-total

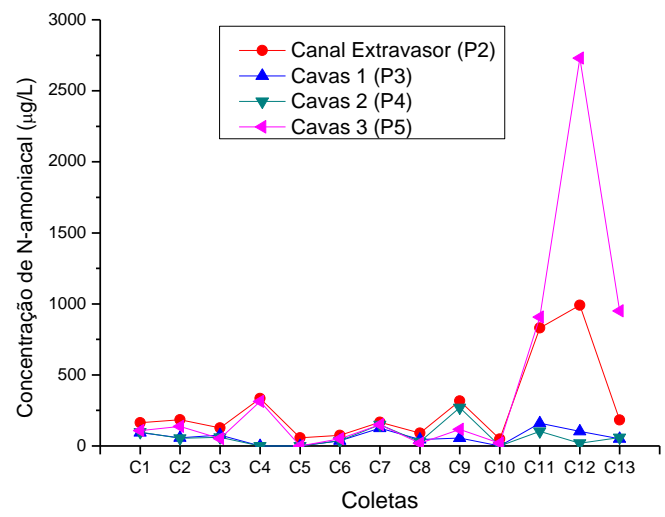

b) Variação da concentração de N-amoniacal

A variação de P-total, $\mathrm{N}$-amoniacal (Figura 8) e do oxigênio dissolvido (Figura 9) na cava 3 (ponto P5) está relacionada com a influência do canal extravasor (P2) que carreou nutrientes para esta cava, levando ao crescimento das macrófitas, que ao se decomporem liberam nutrientes para o canal e menor concentração de oxigênio dissolvido.

A Figura 10 ilustra a conectividade superficial de cavas a montante da BR277 que diferem de outros ambientes de cavas. Enquanto nos demais, as cavas se apresentam como várias lagoas isoladas, nesse ambiente da ilha fluvial, pode-se identificar a existência de grandes sistemas, repletos de reentrâncias e diferentes profundidades.

Figura 9 - Variação da concentração de oxigênio dissolvido $\left(\mathrm{Mg} \mathrm{L}^{-1}\right)$ nos pontos amostrados nas cavas

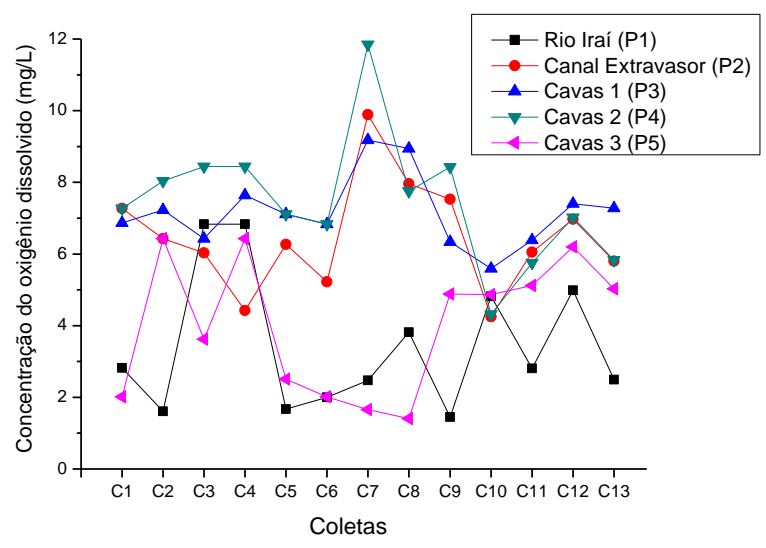




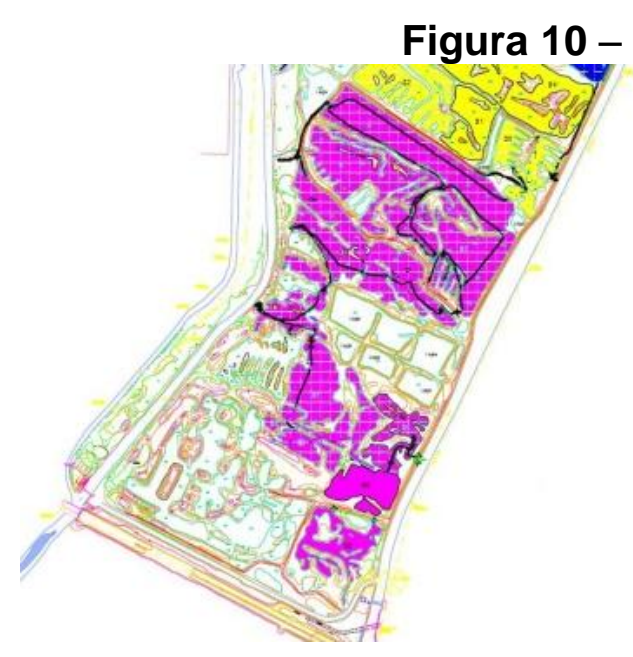

a) Ambiente interligado

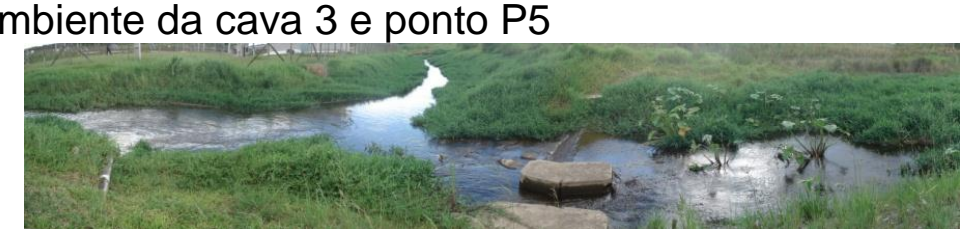

b) $14 / 01 / 2009$

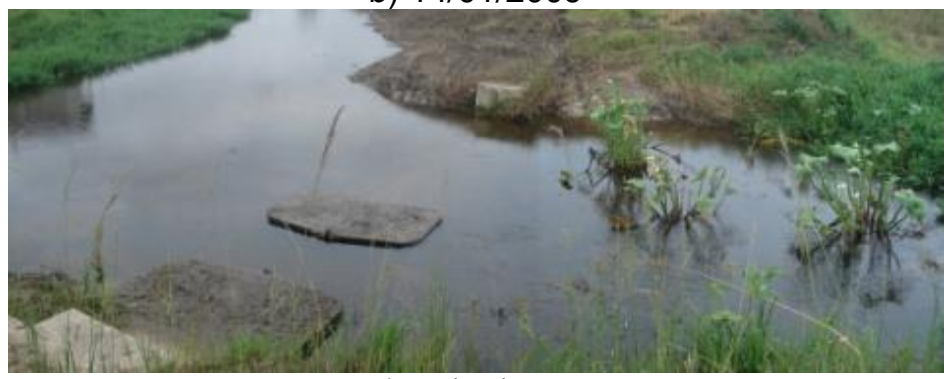

c) $03 / 02 / 2009$

Fotos do autor.

O ambiente (Figura 10a) abrange uma superfície total de 340.985,00 $\mathrm{m}^{2}$. Em 14/01/2009 bombas estavam operando lançando as águas dos ambientes de cavas no canal alimentador da captação BR-277 (Figura 10b). Ao mesmo tempo, as águas passavam sobre a soleira no sentido cava - canal. Em 03/02/2009, a situação, era distinta: Canal paralelo - canal alimentador - cava se conectavam em nível (Figura 10c). E, ao final do período de avaliação, apresentavam $13 \%$ do ambiente coberto de macrófitas aquáticas, correspondendo ao trecho de jusante conectado com 0 canal paralelo.

Rios da Bacia do Altíssimo Iguaçu

Os resultados obtidos nas amostragens de alguns rios da bacia hidrográfica do Alto Iguaçu apresentaram grande influência de esgotos domésticos, que foi comprovado pelos altos valores de E. coli. O mesmo pode ser observado pelos valores de $\mathrm{DBO}$, nitrogênio amoniacal e fósforo total, sendo que os pontos dos rios Atuba e Iguaçu apresentam maior degradação. Isto, provavelmente, está relacionado com o fato de um dos pontos amostrados no rio Atuba se localizar logo após a saída da ETE Atuba Sul, a qual aumenta a concentração de $\mathrm{N}$-amoniacal e P-total, pois o tipo de tratamento adotado (anaeróbio) nesta ETE não remove nutrientes. Como o ponto amostrado no rio Iguaçu é a jusante da ETE Atuba Sul 
(aproximadamente 600 metros) esta carga também pode estar contribuindo com os valores obtidos neste rio.

Assim como o rio Pequeno, o rio Itaqui apresenta menor influência de esgotos domésticos, podendo ser resultado da existência de uma lagoa idealizada como pesque-pague (Figura 11) que recebe a poluição difusa proporcional à densidade demográfica da bacia e o efluente da ETE Martinópolis.

Figura 11 - Lagoa do Rio Itaqui

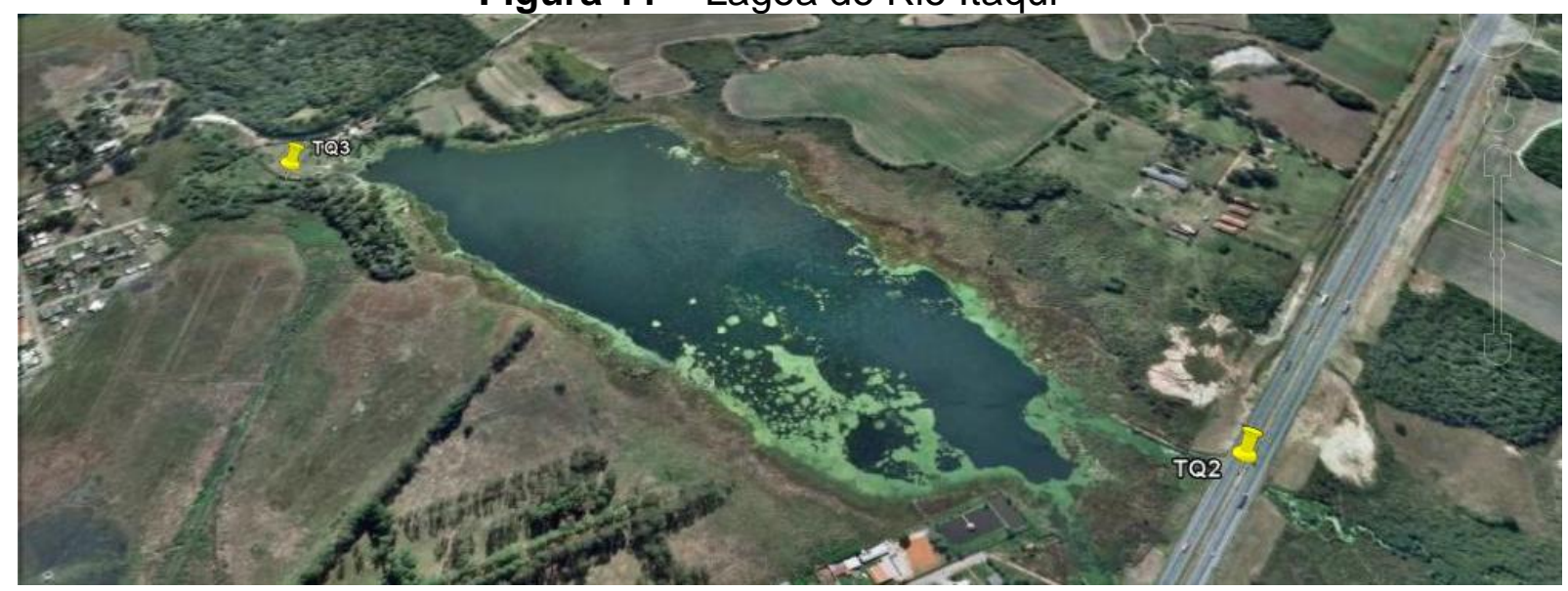

Fonte: adaptada de Google earth

A entrada da lagoa apresentou maiores valores de alguns parâmetros em relação a sua saída (Tabela 2 ), indicando que a lagoa atua como um sistema de absorção de nutrientes, principalmente pelo fato de facilmente ocorrer o domínio de macrófitas aquáticas. Isto ocorre tanto pela entrada de nutrientes (concentração de fósforo total, ortofosfato e $\mathrm{N}$-amoniacal) como também pelo fato do sedimento desta lagoa estar rico de matéria orgânica e nutrientes que são liberados pela decomposição, o que pode ser confirmado pelos valores dos mesmos nutrientes na saída da lagoa do Itaqui.

Tabela 2 - Variação de alguns parâmetros na entrada e saída da Lagoa do Itaqui.

\begin{tabular}{ccc}
\hline Parâmetros & Entrada da lagoa & Saída da lagoa \\
\hline DBO $(\mathrm{mg} / \mathrm{L})$ & $4400 \pm 2890$ & $2900 \pm 669$ \\
Ortofosfato $(\mu \mathrm{g} / \mathrm{L})$ & $310 \pm 390$ & $100 \pm 166$ \\
P-total $(\mu \mathrm{g} / \mathrm{L})$ & $660 \pm 520$ & $470 \pm 230$ \\
$\mathrm{~N}$-amoniacal $(\mu \mathrm{g} / \mathrm{L})$ & $2410 \pm 3210$ & $1060 \pm 1760$ \\
$E$. coli $(\mathrm{NMP} / 100 \mathrm{~mL})$ & $207000 \pm 147000$ & $7000 \pm 640000$ \\
\hline
\end{tabular}

A lagoa do Itaqui e as estruturas São Judas e Cidade Jardim atuam como wetland, mas sem manejo adequado, pois com a entrada de muito nutriente 
(esgotos), as macrófitas dominam e tornam o meio rico em matéria orgânica em decomposição (odores desagradáveis). Neste caso, estes ambientes deveriam ter uma melhor gestão. A questão do manejo das macrófitas aquáticas merece fazer parte da agenda do órgão gestor dos recursos hídricos. Além de se apresentarem como indicadoras ambientais, por serem parte integrante dos ecossistemas aquáticos, desempenham funções vitais a manutenção dos mesmos. Certamente a prática de manejo a ser adotada por recomendação do órgão gestor de recursos hídricos e/ou órgão ambiental estadual será outra que não a soltura rio abaixo.

A variação da qualidade da água no rio Palmital, certamente, está relacionada com a densidade populacional da região, principalmente pela influência direta de esgotos, como mostra a Figura 12a. Esta influência da entrada de esgotos domésticos no percurso do rio Palmital pode ser confirmada também pela variação da DBO (Figura 12b); nitrogênio amoniacal (Figura 12c); fósforo total (Figura 12d); ortofosfato (Figura 12e) e concentração de cafeína (Figura 13). Estas variações estão mais relacionadas com entrada de esgotos domésticos, principalmente a cafeína que não é encontrada em ambientes aquáticos continentais e é bastante consumida pela população. 
Figura 12 - Variação da quantidade de e. coli (nmp/100 ml) e da concentração de demanda bioquímica de oxigênio, $n$-amoniacal, fósforo total, ortofosfato e oxigênio dissolvido nos pontos amostrados no rio Palmital

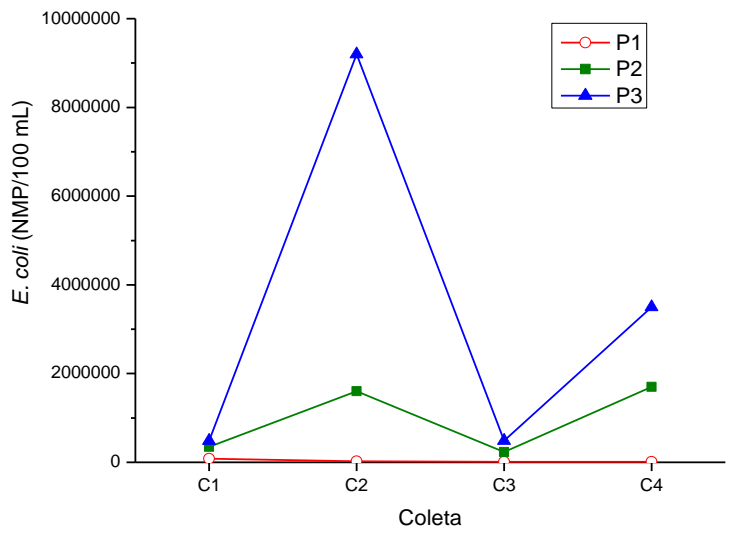

a)Variação da quantidade de E. coli

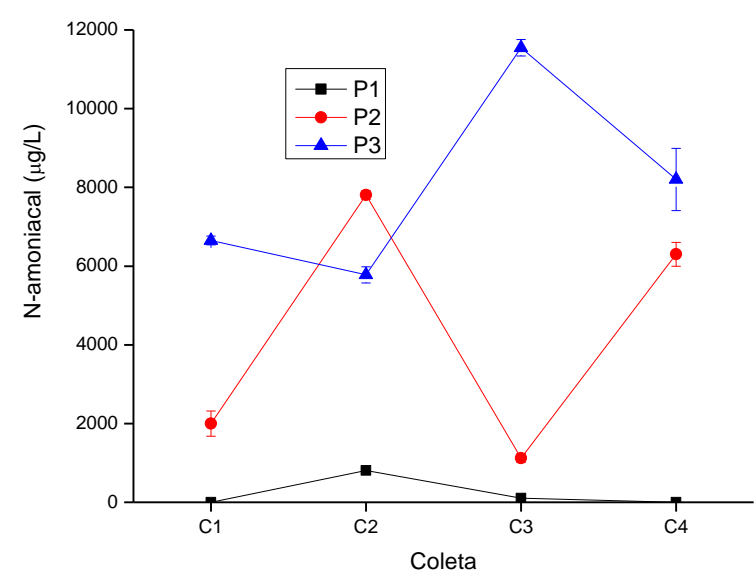

c) Variação da concentração do N-amoniacal

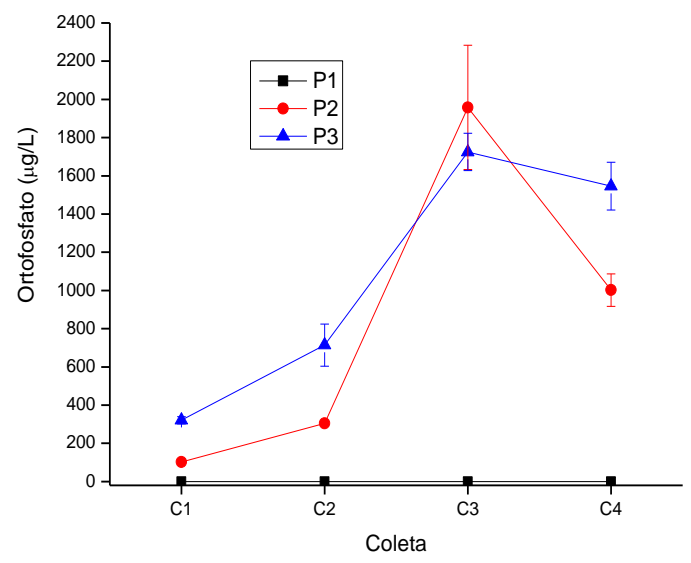

e) Variação da concentração de ortofosfato

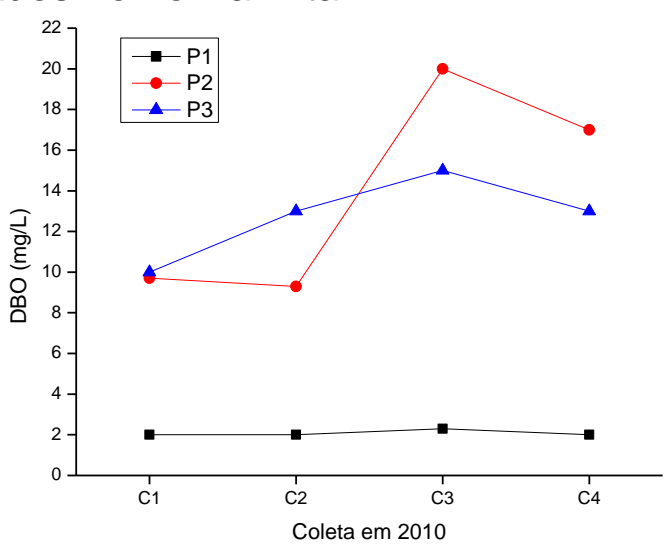

b) Variação da concentração de DBO

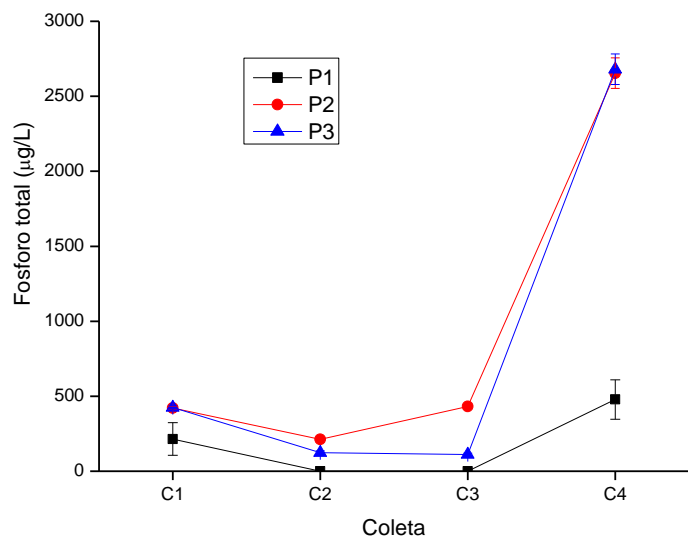

d) Variação da concentração de fósforo total

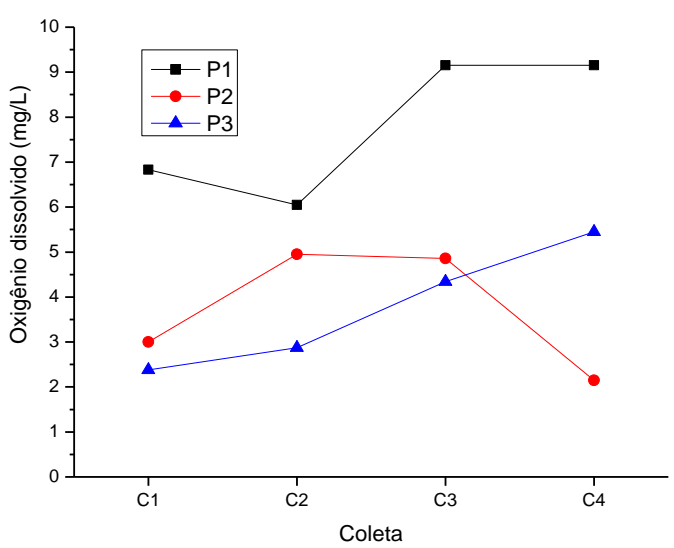

f) Variação da concentração do oxigênio dissolvido

Pontos amostrados: P1 na EMBRAPA (Colombo); P2 a jusante da Vila Zumbi dos Palmares; P3 próximo de sua foz

Campanhas: C1 (8/2/2010); C2 (4/5/2010); C3 (3/8/2010); C4 (16/11/2010) 
Figura 13 - Variação da concentração de cafeína no rio Palmital

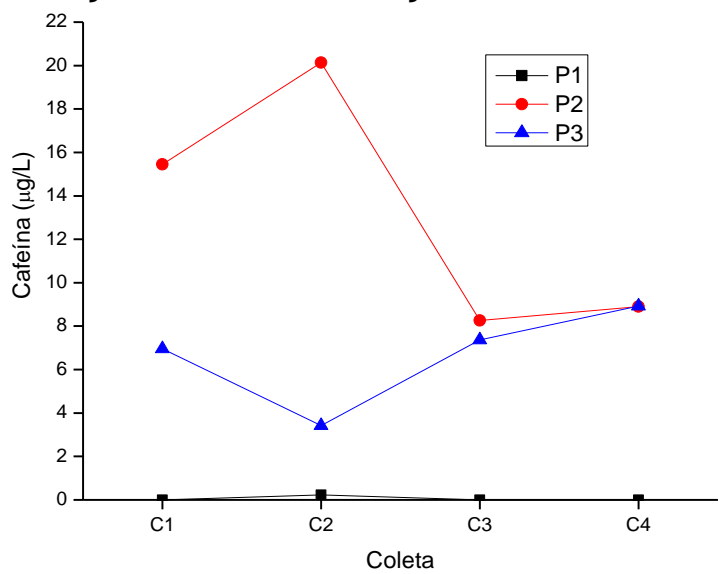

Pontos amostrados: P1 na EMBRAPA (Colombo); P2 a jusante da Vila Zumbi dos Palmares; P3 próximo de sua foz

Campanhas: C1 (8/2/2010); C2 (4/5/2010); C3 (3/8/2010); C4 (16/11/2010)

Projetos e Agentes Atuais de Apropriação do Espaço

A qualidade de vida nas cidades, juntamente com o questionamento de novos parâmetros de desenvolvimento, tem conduzido a discussões interdisciplinares, que se centralizam na concepção de uma ocupação mais coerente e de espaços construídos, social e ambientalmente, mais justos e harmoniosos.

As várzeas, na unidade hidrográfica do Alto Iguaçu, na RMC, foram reconhecidas como muito alta, em termos de importância biológica e prioridade de ação para a conservação da biodiversidade, assim descritas em mapa de áreas prioritárias, que sinaliza com a criação de uma Unidade de Conservação de Proteção Integral, no âmbito do Sistema Nacional de Unidades de Conservação da Natureza - SNUC (MMA, 2007) (Figura 14a). O Governo do Estado, também, consolida a diretriz de instituição de instrumento legal de proteção das várzeas do Iguaçu, proposta constante do Plano de Desenvolvimento Integrado da Região Metropolitana de Curitiba-2006 e declara como Área de Interesse Especial Regional do Iguaçu (AIERI) as áreas contíguas ao leito do Rio Iguaçu, (COMEC, 2008) no trecho compreendido entre as barragens até o início da Área de Proteção Ambiental da Escarpa Devoniana (Figura 14b). 


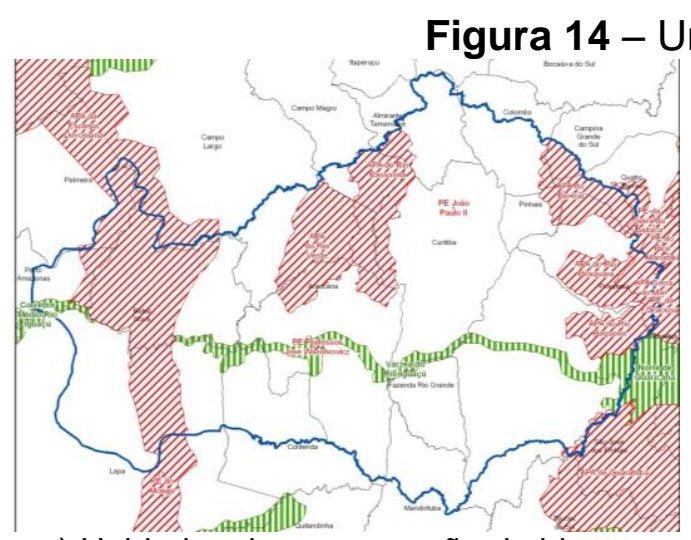

a) Unidades de conservação de biomas

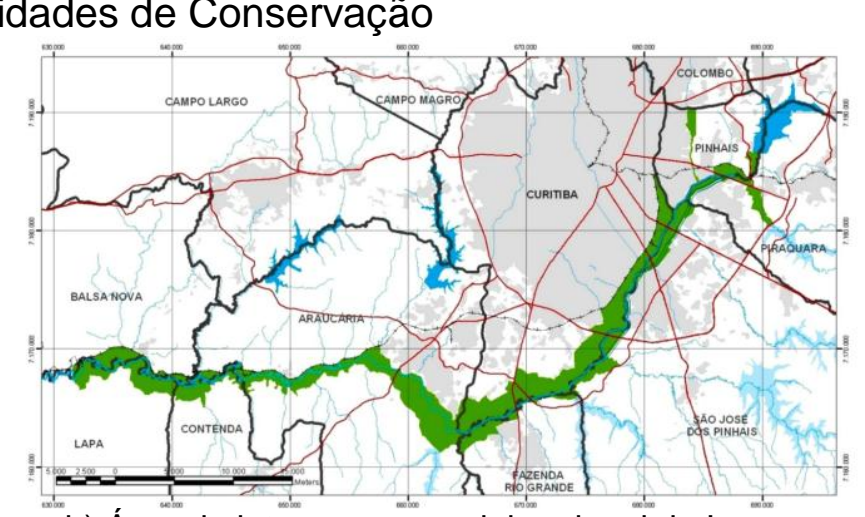

b) Área de interesse especial regional do Iguaçu

पIII
IIIIIII

Áreas prioritárias protegidas dos biomas brasileiros Novas áreas prioritárias de conservação dos biomas brasileiros Delimitação AIERI

Fonte de dados: SUDERSA, 2001; SEMA, 2004; MMA, 2007; COMEC, 2008

O local a montante da BR-277 (Altíssimo Iguaçu) está bastante alterado, não só pela extração de areia, que resultou em quantidade expressiva de cavas de áreas e profundidades totalmente desiguais, algumas estanques, outras interligadas, proporcionando o desenvolvimento de comunidades florísticas (e, provavelmente faunísticas), mas também pelos efluentes de estiagem das redes de galerias de águas pluviais da margem esquerda do canal de água limpa. A oscilação do nível do rio influencia essas áreas alagadas de diferentes maneiras, dependendo da conexão entre estes dois ambientes, que pode ser temporária ou permanente. Algumas áreas alagadas podem estar atuando em certas épocas do ano como canais naturais, contendo água corrente, e merecem ser melhor investigadas (Figura 15).

Figura 15 - Cavas a montante da BR-277
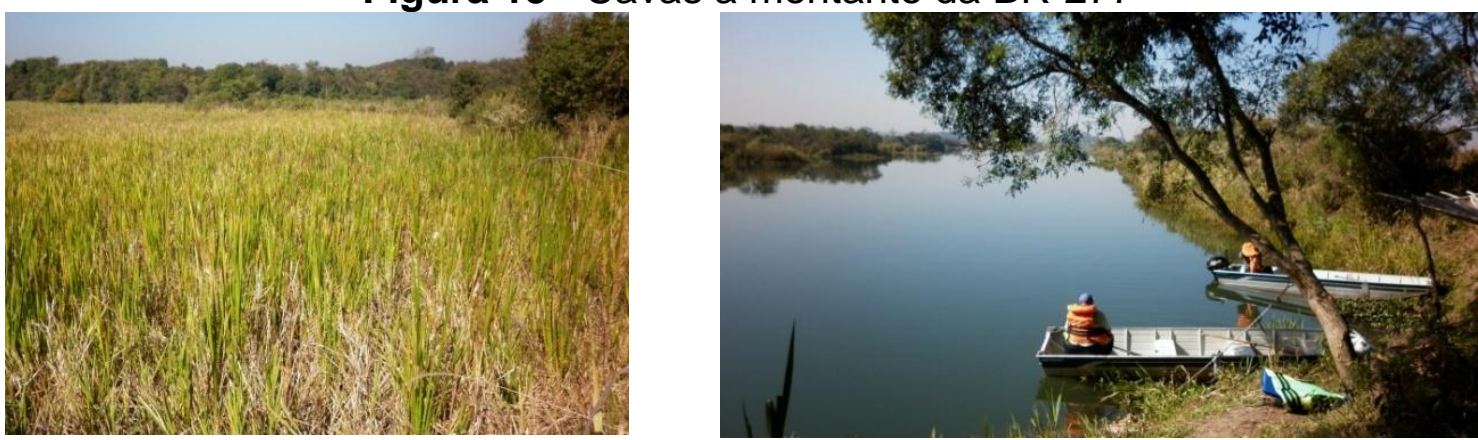

Fotos do autor: 17/06/2011 


\section{CONCLUSÃO E RECOMENDAÇÕES}

A dependência da disponibilidade hídrica de uma metrópole é um fator essencial para as possibilidades de promoção do seu desenvolvimento e manutenção das condições de atratividade, quer em cenários próximos, quer em cenários futuros. Portanto, a degradação da qualidade nos ambientes urbanos da Metrópole impõe a busca de alternativas que devem ser assimiladas enquanto investimentos, pois serão recuperados evitando-se assim, gastos sociais maiores no futuro. Hoje, faz-se necessário compreender adequadamente os sistemas e os serviços que prestam sob pena de correr o risco de não poder romper o círculo constituído pela pressão, impactos e respostas que se manifestam na degradação das águas.

O sistema rio-planície fluvial é um só. $\mathrm{Na}$ área pesquisada, observou-se que não se tem rio saudável sem planície fluvial, e não se tem várzea saudável sem rio saudável. O desafio para a gestão é ter a medida certa entre quanto, onde e como conservar e recuperar e com que objetivos a serem alcançados a curto, médio e longo prazo. Tanto a recuperação quanto a conservação das wetlands passam, também, pela recuperação da qualidade das águas que por elas fluem.

A alternativa de não agir não é uma solução viável, resultando na continuação ou piora nos resultados de qualidade da água observados nos diferentes ambientes aqui avaliados, já não condizentes com a necessidade de garantia dos múltiplos usos, havendo uma necessidade de diminuir esta entrada de nutrientes/poluentes de fontes pontuais e difusas lançadas no rio.

Além de considerar os instrumentos de gestão urbanística, ambiental e de recursos hídricos é necessário a integração das políticas públicas no âmbito da bacia hidrográfica, apresentando potencial para uma discussão da política de desenvolvimento sustentável de toda uma região e da apropriação e proteção das wetlands, em especial.

A água deve ser considerada como elemento principal na concepção das unidades de conservação e como principal objeto da proteção ambiental. Restauração, conservação e preservação do ecossistema wetlands e das suas funções e valores ambientais poderiam ser integrados nos planos de gestão das bacias hidrográficas, contribuindo para o alcance dos objetivos de qualidade e 
disponibilidade hídrica capaz de suportar os usos mais exigentes, pactuados no comitê de bacia e expressos em termos de enquadramento e plano de investimento desenhado com base em metas progressivas.

Caso se proceda à implantação dos controles de vazão sem considerar associada aos controles da qualidade das águas do escoamento superficial urbano, ou, ainda, se perpetue tratamentos ineficientes de esgotos, águas carregadas da poluição das cidades continuarão a alimentar os rios urbanos e a melhoria da qualidade das suas águas será no mínimo limitada. Determinar o limite de depuração do ambiente das cavas (capacidade de carga), aliar as oportunidades econômicas ainda inexploradas no uso de wetlands alteradas das várzeas, nos aspectos paisagísticos e de educação ambiental, e as formas de agir para construir segurança em relação aos riscos ambientais sobre os rios são alguns dos conteúdos estratégicos numa proposta orientada para a sustentabilidade, que a gestão dos recursos hídricos tem o desafio de encaminhar.

Os principais padrões espaciais a serem restaurados serão os fluxos laterais do escoamento, onde o objetivo é de restaurar a função de tamponamento de nutrientes pelas várzeas (riparian wetlands). Neste caso, a zona urbana, a várzea, o rio e os fluxos dos escoamentos superficiais e subsuperficiais comporão a unidade de gestão, de modo a captarem os lixiviados das encostas e a receberem as galerias de águas pluviais e valas de sistema unitário (valas nas regiões sem rede coletora de esgotos) e, também, efluentes de ETEs.

Onde os eventos de cheia se tornaram raros ou localizados, a unidade deve objetivar restaurar a conectividade hidrológica e da vegetação associada à wetland através da conexão de remanescente disponível de vegetação da várzea com a área de várzea a ser restaurada. Os remanescentes de planície de inundação a montante, o rio e variação sazonal de vazão e a área a ser restaurada compõem a unidade neste caso.

Sem intervenção, as águas dos afluentes, e o rio Belém é um destes, com qualidade aquém da necessária para os usos múltiplos, continuarão a comprometer a qualidade dos espaços urbanizados e do rio Iguaçu.

O trecho de montante do Iguaçu apresenta o potencial de redução das cargas em parques - tratamento com o reuso adaptado das históricas cavas de extração de areia, principalmente, e do canal do parque regional do Iguaçu, de modo 
que possam ser empregadas como estruturas de tratamento integrado e controlado. canal e as cavas podem demonstrar os benefícios do uso inovador das estruturas históricas como componentes de um sistema de tratamento que não apresenta potencial para impactar negativamente essas estruturas, desde que exista manejo.

A primeira função será o tratamento de águas. As funções seguintes incluem proteção da reserva de água potável, melhoria dos acessos públicos às cavas históricas e melhoria do entendimento público dos aspectos da qualidade da água através da demonstração de estratégias inovadoras de melhoria da qualidade da água.

A requalificação das cavas permitirá visualizar uma forma mais natural, bonita e efetiva de tratamento das águas da metrópole. E, essas wetlands, que além de Typha dominguensis Pers. (taboa) poderão produzir muitas outras plantas e flores, permitirão ampliar a beleza e o perfume do ambiente, produzirão água de boa qualidade, melhorarão a qualidade do entorno imediato e ao mesmo tempo propiciarão uma fonte de renda para a população envolvida com o manejo, comercializando ou não as plantas utilizadas nos sistemas.

\section{REFERÊNCIAS}

AGUASPARANA - INSTITUTO DAS ÁGUAS DO PARANÁ. Relatório do diagnóstico da bacia do Alto Iguaçu. Curitiba, 2011a.

Sistema de Informações Hidrológicas. Curitiba, 2011b.

ALMEIDA, F. Os desafios da sustentabilidade. 2. ed. Rio de Janeiro: Elsevier, 2007.

APHA - American Public Health Association. Standard Methods for the examination of water and wastewater. $20{ }^{\mathrm{ed}}$. Washington: APHA-AWWA-WEF, 1998.

BERTRAND, G; BERTRAND, C. Uma geografia transversal e de travessias: o meio ambiente através dos territórios e das temporalidades. organizador PASSOS, M. M. dos. Maringá: Ed. Massoni, 2007. 332p.

BRIX, H.; ARIAS, C. A. The use of vertical flow constructed wetlands for on-site treatment of domestic wastewater: New Danish guidelines. Ecological Engineering, 25 (5), p. 491- 500, 2005.

BUSTOS ROMERO, M. A. A arquitetura bioclimática do espaço público. Brasília: Editora Universidade de Brasília, 2007. 226p. 
CHARMAN, K. "A Sewer Becomes a Water Park." Yes! Magazine. Winter 2004: Whose Water? Disponível em: <http://www.yesmagazine.org> Acesso em: 16/12/2008.

COMEC - COORDENAÇÃO DA REGIÃO METROPOLITANA DE CURITIBA. Área de interesse especial regional do Iguaçu. Curitiba, 2008.

CORTES, R. M. V.; OLIVEIRA, D. G.; LOURENÇO, J. M.; FERNANDES, L. F. S. Bioengineering techniques in the rehabilitation of lotic and lentic systems: Two case studies in Portugal. Trabalho apresentado em 5th International Symposium of Ecohydraulics, Madrid, 2004.

CWP - CENTER FOR WATERSHED PROTECTION. Technical report. Stormwater BMPs in Virginia's James river basin: an assessment of field conditions \& programs. Jun 2009. Disponível em: http://www.cwp.org. Acesso em 21/7/2009.

DUARTE, O.; GUINSKI, L. A. Imagens da evolução de Curitiba. Curitiba: Duarte, 2002. 288p.

FATMA - Fundação de Meio Ambiente de Santa Catarina. Atlas ambiental da região de Joinvile: complexo hídrico da baía de Babitonga. Florianópolis: 2002.

IBAMA - INSTITUTO BRASILEIRO DO MEIO AMBIENTE E DOS RECURSOS NATURAIS RENOVÁVEIS. Guia de chefe. dezembro de 2000. Disponível em: http://www.ibama.gov.br. Acesso em: 20/12/2010.

JAPÃO, Ministério de obras públicas. Purificação eficiente valendo-se do ambiente natural do rio Tama: estação de purificação Nogawa, estação de purificação Hirasegawa, estação de purificação Yajigawa. Bureau de Kanto, Escritório de obras KEIHIN, 198-? 18p.

KONNERUP, D.; BRIX, H. Use of ornamental plants to enhance the public perception of constructed wetlands systems. Trabalho apresentado em 8th INTECOL International Wetlands Conference, Cuiabá, 2008.

LANGE, F. L. P. Iguaçu: um caminho pelo rio. Curitiba: F.L.P. Lange, 2005.

LAUGESEN, C.H.; FRYD, O.; KOOTTATEP, T.; BRIX, H..Sustainable wastewater management in developing countries: new paradigms and case studies from the field. Reston: American Society of Chemical Engineers Press, 2010.

MITSCH, W.J.; GOSSELINK, J. G. Wetlands 3.ed. John Wiley and Sons, 2000, 936 p. Disponível em: http://www.google.com.br/books. Acesso em: 25/07/2007.

MMA - Ministério do Meio Ambiente, Secretaria de Recursos Hídricos. Plano Nacional de Recursos Hídricos. Panorama e estado dos recursos hídricos do Brasil: v 1. Brasília: MMA, 2006a.

Mapa de áreas prioritárias. Disponível em: http://mapas.mma.gov.br. Acesso em: 17/07/ 2007. 
MOLLE, P.; LIENARD, A.; BOUTIN, C.; MERLIN, G.; IWEMA, A. How to treat raw sewage with constructed wetlands: an overview of the French systems. Water, Science, and Technology, 51(9), p. 11-21, 2005.

NEIFF, J. J. El regimen de pulsos en rios y grandes humedales de Sudamérica. In: Topicos sobre humedales subtropicales y templados de Sudamérica. UNESCO, ORCYT (Uruguay). 1999. Disponível em: http://unesco.org. Acesso em: 04/6/2008.

NOVILLO, M. G. The ecohydrology regional programme for Latin America and the Caribbean. Trabalho apresentado em 8th INTECOL International Wetlands Conference, Cuiabá, 2008.

OAI - Ocean Arks International. Disponível em: <http://www.oceanarks.org>. Acesso em: 04 jun. 2008.

ODUM, E. P. Ecologia. Rio de Janeiro: Editora Guanabara, 1988.

SAHAGIAN, G.; MELACK, J. Global wetlands distribution and functional characterization: trace gases and the hydrologic cycle. Report from the Joint GAIM, BAHC, IGBPDIS, LUCC Workshop. Santa Barbara, 1998.

SCHUYT, K.; BRANDER, L. Living Waters. Conserving the source of life. The Economic Values of the World's Wetlands. WWF-International, Gland, Switzerland/ Institute for Environmental Studies Vrije Universiteit Amsterdam, The Netherlands. Gland/Amsterdam, January 2004. 32p.

SEMA - Secretaria de Estado do Meio Ambiente e Recursos Hídricos. Limites municipais, 2004

SUDERHSA - SUPERINTENDÊNCIA DE DESENVOLVIMENTO DE RECURSOS HÍDRICOS E SANEAMENTO AMBIENTAL. Sistema de Informações Geográficas, 2001.

Plano diretor de drenagem para a bacia do rio Iguaçu na região metropolitana de Curitiba. Relatório final. Volume 4. Capacidade do sistema atual e medidas de controle de cheias. Tomo 4.30. Estudo dos efeitos das medidas de controle propostas sobre o rio Iguaçu. 2002.

Plano da bacia do Alto Iguaçu e afluentes do Alto Ribeira. Relatório de diagnóstico, novembro 2007.

TASSI, R. Determinação do hidroperíodo em terras úmidas a partir de indicadores biológicos e uso no gerenciamento dos recursos hídricos. 244p. Tese (Doutorado em Recursos Hídricos e Saneamento Ambiental) - Universidade Federal do Rio Grande do Sul, Porto Alegre, 2007.

TREVISAN, E. O meio físico e a ocupação urbana de Curitiba, Paraná: estudos de caso. In: MENDONÇA, F. (org.). Cidade, ambiente \& desenvolvimento: abordagem interdisciplinar de problemáticas socioambientais urbanas de Curitiba e RMC. Curitiba: Editora UFPR, 2004. 
VERHOEVEN, J. T. A.; SOONS, M. B.; JANSSEN, R.; OMTZIGT, N. An operational landscape unit approach for identifying key landscape connections in wetland restoration. Journal of Applied Ecology, 45, p. 1496-1503, 2008

VITOR, N. A Terra do Futuro: impressões do Paraná. 2. ed. Curitiba: Prefeitura Municipal de Curitiba, 1996. (Coleção Farol do Saber)

VYMAZAL, J.. Plants used in constructed wetlands with horizontal subsurface

YAMAMOTO, C. R. G. Wetlands na Região Metropolitana de Curitiba - PR: diagnóstico, conflitos socioeconômicos e desafios de gestão. 173p. Tese (Doutorado em Geografia) - Setor de Ciências da Terra, Universidade Federal do Paraná, Curitiba, 2011.

(Recebido em 28.11.2011. Aceito em 14.06.2012) 